\title{
Embedding Sensors in 3D Printed Metal Structures
}

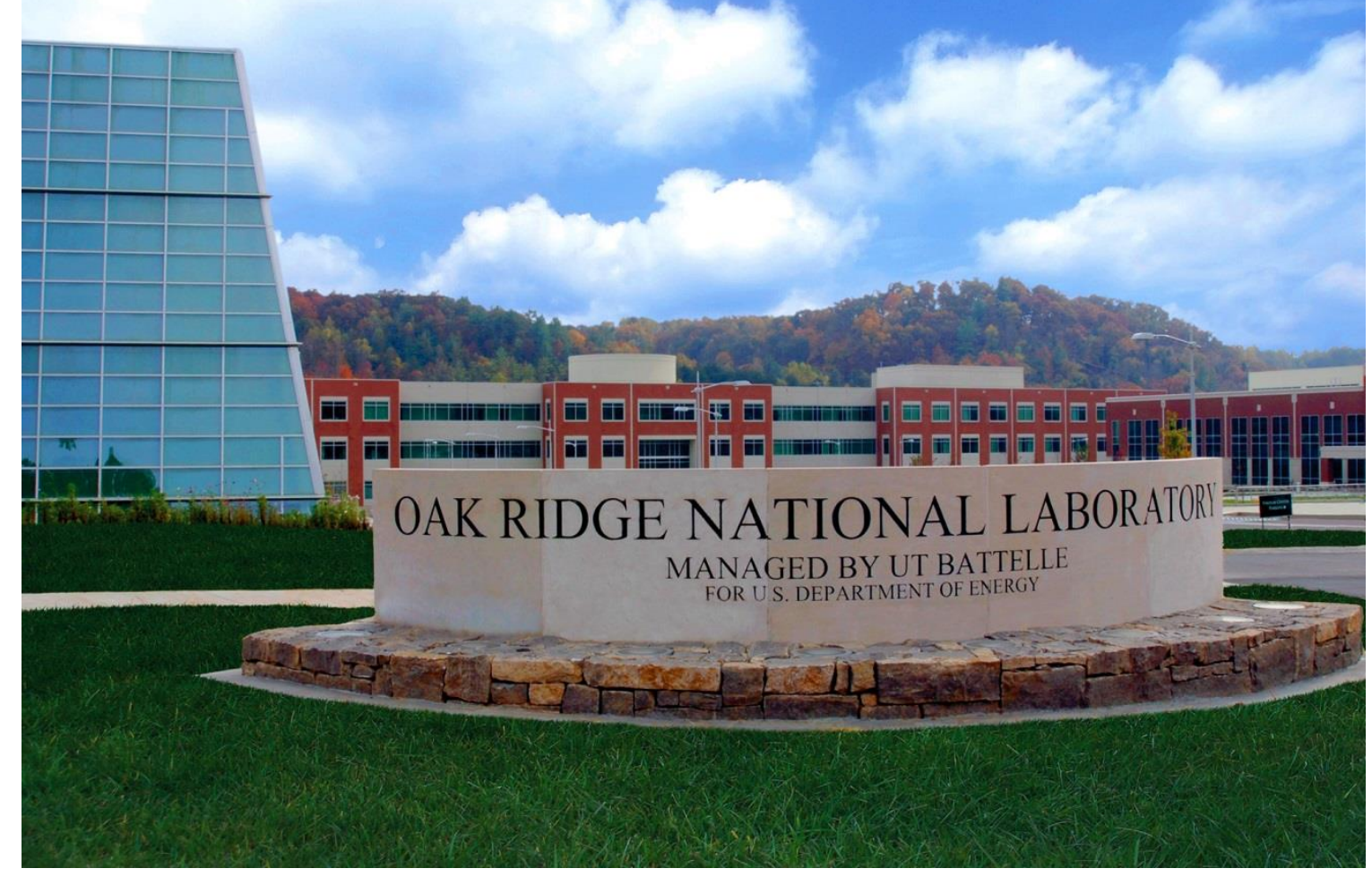

Holden C. Hyer

Keith Carver

Fred A. List III

Christian M. Petrie

August 2021

M3TC-21OR0404044

Approved for public release.

Distribution is unlimited. 


\title{
DOCUMENT AVAILABILITY
}

Reports produced after January 1, 1996, are generally available free via US Department of Energy (DOE) SciTech Connect.

Website www.osti.gov

Reports produced before January 1, 1996, may be purchased by members of the public from the following source:

\author{
National Technical Information Service \\ 5285 Port Royal Road \\ Springfield, VA 22161 \\ Telephone 703-605-6000 (1-800-553-6847) \\ TDD 703-487-4639 \\ Fax 703-605-6900 \\ E-mail info@ntis.gov \\ Website http://classic.ntis.gov/
}

Reports are available to DOE employees, DOE contractors, Energy Technology Data Exchange representatives, and International Nuclear Information System representatives from the following source:

Office of Scientific and Technical Information

PO Box 62

Oak Ridge, TN 37831

Telephone 865-576-8401

Fax 865-576-5728

E-mail reports@osti.gov

Website http://www.osti.gov/

This report was prepared as an account of work sponsored by an agency of the United States Government. Neither the United States Government nor any agency thereof, nor any of their employees, makes any warranty, express or implied, or assumes any legal liability or responsibility for the accuracy, completeness, or usefulness of any information, apparatus, product, or process disclosed, or represents that its use would not infringe privately owned rights. Reference herein to any specific commercial product, process, or service by trade name, trademark, manufacturer, or otherwise, does not necessarily constitute or imply its endorsement, recommendation, or favoring by the United States Government or any agency thereof. The views and opinions of authors expressed herein do not necessarily state or reflect those of the United States Government or any agency thereof. 
Transformational Challenge Reactor

\title{
EMBEDDING SENSORS IN 3D PRINTED METAL STRUCTURES
}

\author{
Holden C. Hyer \\ Keith Carver \\ Fred A. List III \\ Christian M. Petrie
}

August 2021

Milestone \#: M3TC-21OR0404044

\author{
Prepared by \\ OAK RIDGE NATIONAL LABORATORY \\ Oak Ridge, TN 37831-6283 \\ managed by \\ UT-BATTELLE LLC \\ for the \\ US DEPARTMENT OF ENERGY \\ under contract DE-AC05-00OR22725
}





\section{CONTENTS}

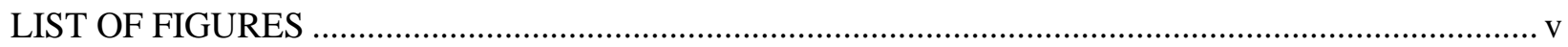

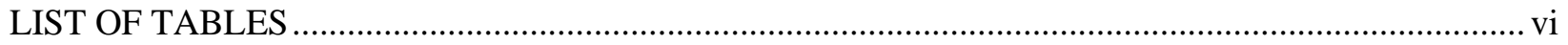

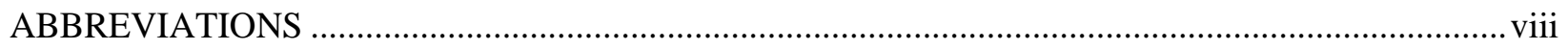

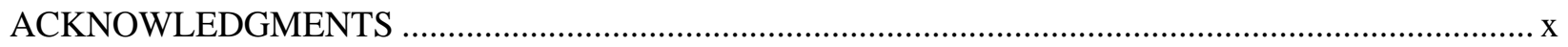

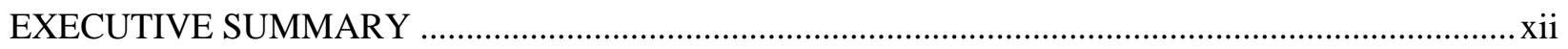

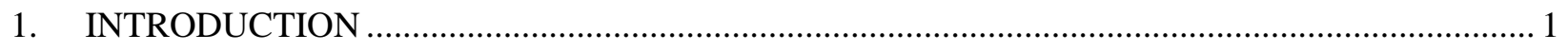

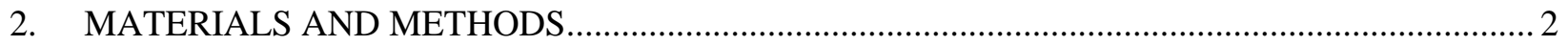

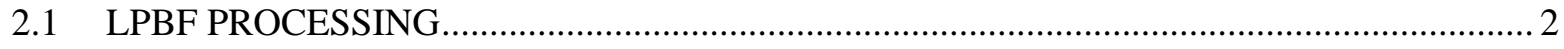

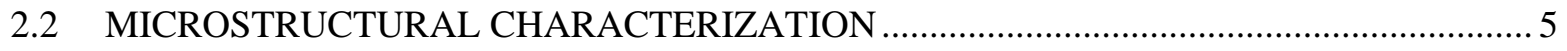

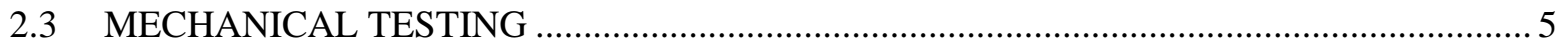

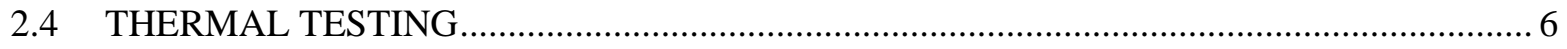

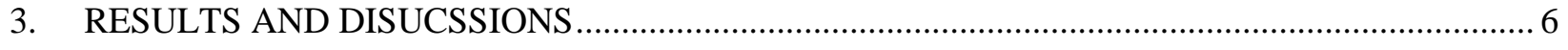

3.1 EFFECT OF LPBF PROCESSING ON SAMPLE FABRICATION …............................... 6

3.2 MICROSTRUCTURAL ANALYSIS OF EMBEDDED SHEATHS …............................... 11

3.3 EMBEDDED THERMOCOUPLE CHARACTERIZATION …....................................... 13

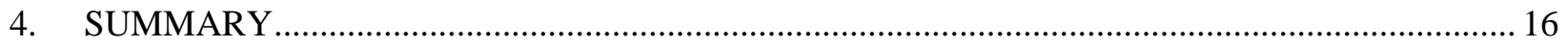

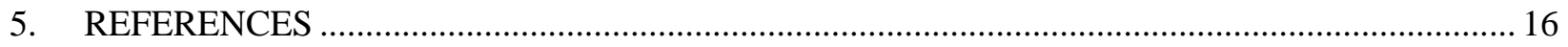





\section{LIST OF FIGURES}

Figure 1. Schematic of a typical LPBF AM process........................................................................ 3

Figure 2. Schematic of the (a) top and (b) side views of the build plates used for embedding the sheaths and thermocouples in SS316. All units shown are in inches..

Figure 3. Photo of the completed builds with embedded sheaths. The samples P1-P4 and P5-P8 had a first layer scan orientation of $0^{\circ}$ and $90^{\circ}$, respectively. The samples labeled P1 and P5 were scanned with a laser dwell time of $100 \mu \mathrm{s}, \mathrm{P} 2$ and P6 using $80 \mu \mathrm{s}, \mathrm{P} 3$ and P7 with $60 \mu \mathrm{s}$, and $\mathrm{P} 4$ and $\mathrm{P} 8$ at $40 \mu \mathrm{s}$.

Figure 4. OM images of the cross sections of the embedded sheaths that were processed with a first layer scan orientation of (a) $0^{\circ}$ and (b) $90^{\circ}$.

Figure 5. Examples of image analysis performed $(\mathrm{a}-\mathrm{d})$ for the amount of open space around the embedded sheaths/thermocouples and $(\mathrm{e}-\mathrm{g})$ for the porosity content in the region built with LPBF. Image analysis was performed by first (a, b, e) importing and selecting the desired the region, (c, f) applying an 8 bit threshold, and (d, g) measuring the area of white space compared with the area of dark space.

Figure 6. Results of the image analysis for the embedded sheaths showing the measured open space of the channel compared with the expected area of the channel width $\times$ depth for the samples with a first scan layer orientation of (a) $0^{\circ}$ and (b) $90^{\circ}$. Data are shown as a function of dwell time. The drawn parallel lines indicate the overall trend of the data. In (a), the $60 \mu$ s sample with a width and depth of 0.05 in. had an approximate open space of $1.31 \mathrm{~mm}^{2}$, due to a large amount of porosity observed in the LPBF built region, and is therefore not shown on the plot.

Figure 7. (a) Plotted porosity content and Vickers hardness of the LPFB build region vs. the dwell time used to process that region. (b-e) OM images of the LPBF built region using dwell times of (b) 100, (c) 80, (d) 60, and (e) $40 \mu \mathrm{s}$. The lines in (a) indicate the overall trend.

Figure 8. (a, b) Low and (c, d) high magnification backscatter electron micrographs showing the interface between the embedded sheath and the LPBF built region when using a first layer scan orientation of (a, c) $0^{\circ}$ and (b, d) $90^{\circ}$. The sheath shown was embedded in a channel with a width/depth of 0.04 in., shown to yield the best result for embedding the sheaths.

Figure 9. Photo of the embedded thermocouples post-LPBF-processing. Six thermocouples were embedded in select channel cavities based on results from the parametric investigation with the embedded sheaths. Additional sheaths were embedded on the right-most channels of the plate to further explore the LPBF processing regime.

Figure 10. $(\mathrm{a}-\mathrm{c})$ Low and $(\mathrm{d}-\mathrm{f})$ high magnification OM images of the cross section of the embedded thermocouples with corresponding channel dimensions of (a, d) 0.04 in. wide and 0.04 in. deep, (b, e) 0.04 in. wide and 0.045 in. deep, and (c, f) 0.045 in. wide and 0.04 in. deep.

Figure 11. Recorded temperatures of thermocouples during furnace heating to $500{ }^{\circ} \mathrm{C}$. The inset plot shows the high consistency between the three embedded thermocouples compared with a nonembedded thermocouple. 


\section{LIST OF TABLES}

Table 1. List of channel dimensions and LPBF processing parameters used to embed the sheaths

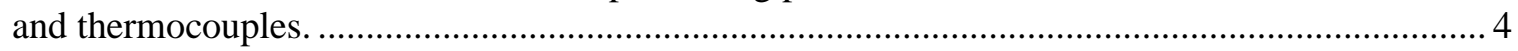

Table 2. Nominal composition of the SS316L powder acquired from Praxair........................................ 5 



\section{ABBREVIATIONS}

$\begin{array}{ll}\text { AM } & \text { additive manufacturing } \\ \text { DED } & \text { direct energy deposition } \\ \text { DOE } & \text { US Department of Energy } \\ \text { LPBF } & \text { laser powder bed fusion } \\ \text { OM } & \text { optical microscopy } \\ \text { ORNL } & \text { Oak Ridge National Laboratory } \\ \text { SEM } & \text { scanning electron microscopy } \\ \text { SS } & \text { stainless steel } \\ \text { TCR } & \text { Transformational challenge Reactor } \\ \text { UAM } & \text { ultrasonic additive manufacturing }\end{array}$





\section{ACKNOWLEDGMENTS}

This research was sponsored by the Transformational Challenge Reactor program of the US Department of Energy's Office of Nuclear Energy. The report was authored by UT-Battelle LLC under contract no. DE-AC05-00OR22725. Victoria Cox and Travis Dixon helped with sample metallography preparation. 



\section{EXECUTIVE SUMMARY}

The Transformational Challenge Reactor (TCR) program is leveraging recent advances in modeling and simulation, materials, and additive manufacturing (AM) technologies to design a modern nuclear reactor. Some of the main TCR technologies include in situ monitoring and the integration of sensors during the manufacturing of quality-significant nuclear reactor components. This report describes the general procedure and process optimization for embedding sensors within generic stainless steel 316 (SS316) components using laser powder bed fusion (LPBF). A more detailed, quality-significant test plan and supporting procedures are available upon request (ORNL/TM-2021/2127). LPBF involves the use of a scanning laser to selectively melt regions of a powder bed, additively building a part layer by layer. This report describes the LPBF processing technique and discusses the effects of LPBF processing parameters on the success of the sensor embedding process. Experiments used machined cavities in the form of channels in an SS316 base for the sensors to lay in while material is additively built over the top, thereby embedding them in an SS316 matrix. A preliminary investigation involved using empty SS316 sheaths as surrogates to explore the effects of various LPBF processing parameters and the dimensional requirements of the machined channels. Microstructural investigations showed that a smaller channel width/depth combination closer to the sensor's diameter was best for the embedding process. After the desired parameters were selected, Type-K thermocouples were embedded and evaluated post-embedding using nondestructive thermal testing, as well as destructive sectioning and microscopy. Post-build characterization showed that the thermocouples were well-bonded to the SS316 matrix and were fully functional after embedding. During thermal testing to temperatures up to $500{ }^{\circ} \mathrm{C}$, the embedded thermocouples read consistently with one another and deviated only slightly from the readings of a nonembedded thermocouple located within the furnace. This slight discrepancy was most likely due to differences in the thermal time constants for a nonembedded thermocouple vs. a thermocouple embedded in a solid SS316 block. The results presented in this report will serve as the foundation for future work that will focus on embedding sensors in relevant TCR reactor components and eventually testing those components under neutron irradiation. 



\section{INTRODUCTION}

The Transformational Challenge Reactor (TCR) program was launched with the goal of designing, additively manufacturing, and operating an advanced nuclear reactor by leveraging recent advances in modeling and simulation, materials, and additive manufacturing (AM) to produce geometries that were considered impossible to achieve via conventional manufacturing techniques [1,2]. These efforts are part of the larger goal to transform the nuclear reactor design, development, and deployment process by producing quality-significant nuclear components with a high pedigree via in situ process monitoring during fabrication and embedded sensors for enhanced performance monitoring during nuclear operation. In particular, the ability to perform site-specific monitoring at critical locations is especially intriguing for microreactor concepts that could eventually support semiautonomous operation to reduce operation and maintenance costs [3]. However, the ability to embed sensors within complex nuclear components or assemblies can prove challenging, especially for in-core components that must survive for extended durations while subject to significant radiation dose and high temperatures.

Temperatures in the TCR core, which are expected to be in the range of $\sim 350$ to $550{ }^{\circ} \mathrm{C}$ [4], are some of the most important parameters that must be monitored. Because TCR is a small gas-cooled system, there are significant spatial variations in the local reactor power, which can lead to large variations in coolant temperatures throughout the core [5]. To monitor these temperature distributions in the components, thermocouples and spatially distributed fiber optic temperature sensors are being considered for embedding within AM components. Type-K thermocouples and silica fiber optics can be used at temperatures generally up to $1,000{ }^{\circ} \mathrm{C}[6,7]$, and there is precedent for using these sensors within nuclear reactors [8-11], making them strong candidates for embedding and monitoring TCR core temperatures. For example, the stainless steel (SS) 316 (SS316) structures that establish the outlet plenum of the core is a prime candidate for embedding sensors to fully map the temperature profile of the various coolant streams and their mixing below the core [1]. Metal AM processes, such as laser powder bed fusion (LPBF), allow for good flexibility in the geometric resolution of complex components because they rely on repetitive local melting ( $<500 \mu \mathrm{m}$ in cartesian space) to fuse a part together [12]. However, LPBF processing produces high thermal gradients due to the high cooling rates observed (orders of $10^{5}-10^{7} \mathrm{~K} \cdot \mathrm{s}$ ${ }^{1}$ [13]), which can induce significant thermal stresses. Moreover, the laser melting process can also damage the sensors during the embedding process if the melt pool is not well controlled. Therefore, the local melting must be tailored for embedding sensors to ensure that specific regions on and near the sensor are embedded without failing the sensor or affecting its calibration as a result of thermal cycling during the LPBF process.

This report summarizes the general process for embedding thermocouples within generic SS316 components via LPBF. A more detailed, quality-significant test plan and supporting procedures are available as controlled documents upon request (ORNL/TM-2021/2127). In addition to describing the process, this report summarizes evaluations of the melt pool depth by using empty sensor sheaths as surrogates to determine the optimum processing parameters for embedding thermocouples. After successfully embedding the thermocouples via the optimized process parameters, the embedded thermocouples were characterized with microscopy and thermal testing to evaluate bonding quality and sensor functionality, respectively. The results presented in this report will serve as the foundation for future work that will focus on embedding sensors in relevant TCR reactor components and eventually testing those components under neutron irradiation. 


\section{MATERIALS AND METHODS}

\subsection{LPBF PROCESSING}

Conventional processes, such as casting and subsequent working/machining of metals, are unsuitable for handling fragile sensors because of the high temperatures needed to melt the bulk metal and/or the induced mechanical strain from working/machining. Additionally, these conventional processes do not offer the same ability to fabricate geometrically complex components with sensors embedded at strategic locations. Petrie et al. [14-16] used ultrasonic AM (UAM) to embed sensors in metals by using a solidstate process (i.e., no melting was required). However, UAM has limits to part complexity and userdefined specifications. AM melting strategies, such as LPBF or directed energy deposition (DED), can be used to fabricate components with greater complexity $[12,17]$ but have scarcely been studied for embedding sensors because of the high process knowledge needed to successfully embed sensors without causing sensor failure. Li et al. [18] attempted to embed fragile fiber-optic sensors in an SS matrix by using DED and successfully bonded the sensors with the matrix. However, only a few layers were deposited before sensor failure, indicating a need for further investigation. Studies by Haverman and coauthors [19-21] have shown more promising techniques utilizing LPBF, resulting in embedded fiber optics in SS316 after placing the sensors within small cavities. However, their work was also limited to demonstrating initial feasibility and lacks processing details and sensor functionality demonstrations.

In LPBF processing, a laser is used to selectively melt regions of a powder bed, fusing a part together in a layer-by-layer process. A schematic of the typical LPBF process using a pulsed laser is shown in Figure 1. As the laser interacts with the powder bed with a user-defined power $(\sim 50-400 \mathrm{~W})$ and a given scan orientation $\left(67^{\circ}\right.$ rotation between consecutive layers), it moves based on a given dwell time $(\sim 40-120 \mu \mathrm{s})$ of the laser at a given point before the pulsed laser jumps to the next point defined by a point distance $(\sim 40-80 \mu \mathrm{m})$. The distance between consecutive laser scans, known as the hatch spacing $(50-200 \mu \mathrm{m})$, can be controlled to ensure that proper overlap occurs to limit porosity from missed regions. Lastly, the powder layer slice thickness can be controlled, which is usually on the order of 30-100 $\mu \mathrm{m}$ based on the average powder particle size. Many LPBF studies have mapped these processing parameters to achieve close to theoretical densities for specific alloys without any other defects, such as cracks or layer delamination $[12,13,17]$. 


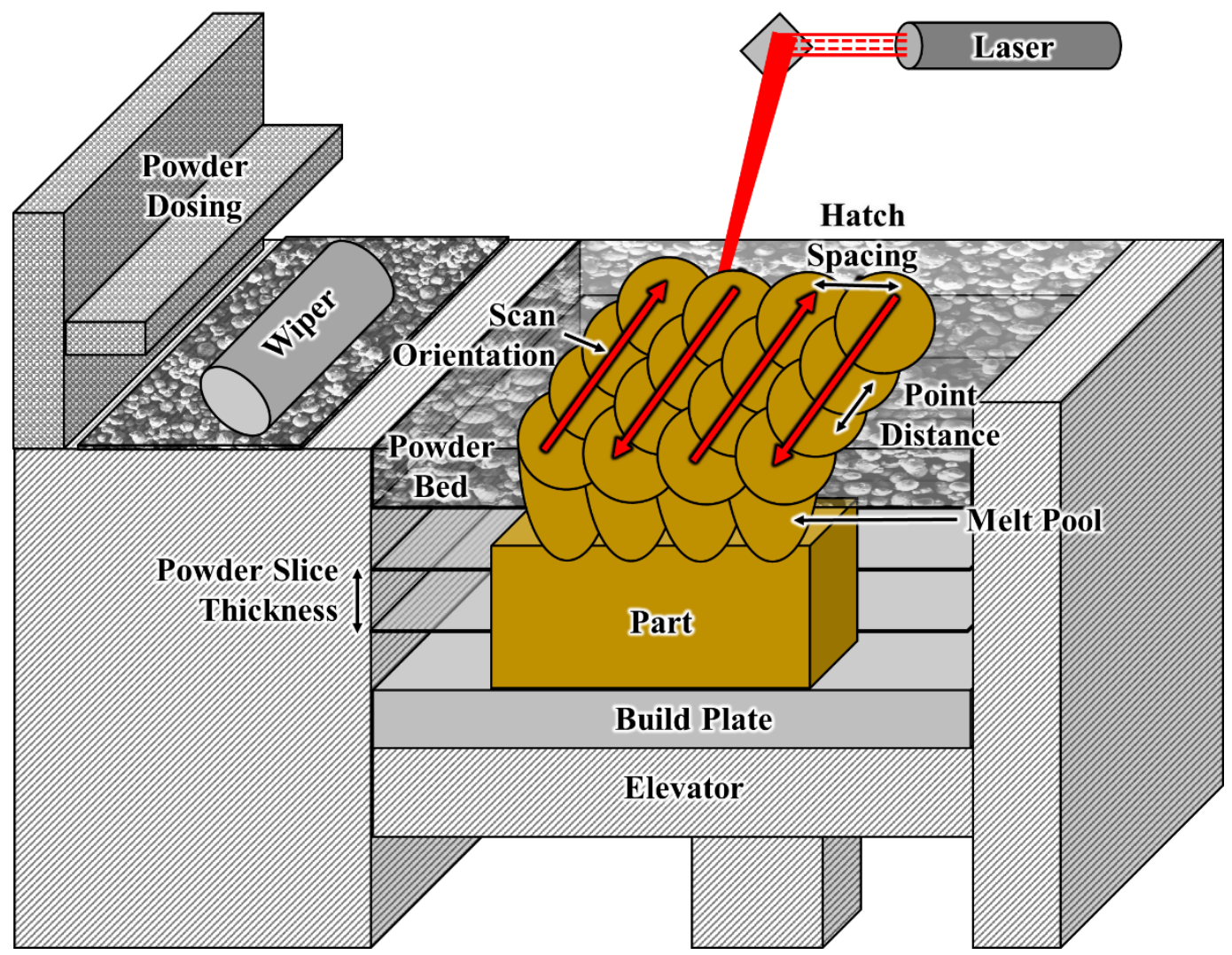

Figure 1. Schematic of a typical LPBF AM process.

Because LPBF relies on a powder bed, a wiper is used to rake the powder and smooth the build surface with a new, even layer of powder after each laser scan, as shown in Figure 1. The wiper levels the powder to a given build plane on which the laser is focused, usually flush with the build chamber floor. Thus, the powder bed and build must remain flush or slightly below the build plane to avoid collisions with the wiper and prevent uneven powder distributions. Adding sensors within the powder bed adds a 3D element to the build. The powder bed is limited to $2 \mathrm{D}$ with respect to the build plane, which must remain flat and even for consistent powder leveling. To keep the sensors below the build plane and reduce any potential interaction with the wiper, channels were machined in the build plate by using electrical discharge machining. The thermocouples that were selected for embedding have a diameter of $0.04 \mathrm{in}$. $(1.02 \mathrm{~mm})$. Because the channel width and depth affect the elevation of the sensor relative to the build plane, these dimensions might also affect the overall quality of the sensor embedding. Therefore, nine different channel geometries were chosen in which the width and depth were varied at 0.04, 0.045, and 0.05 in. (Table 1). Figure 2 provides a schematic that shows the channels within the build plates. Smaller channel dimensions below 0.04 in. were not considered to avoid potential damage to the wiper. 


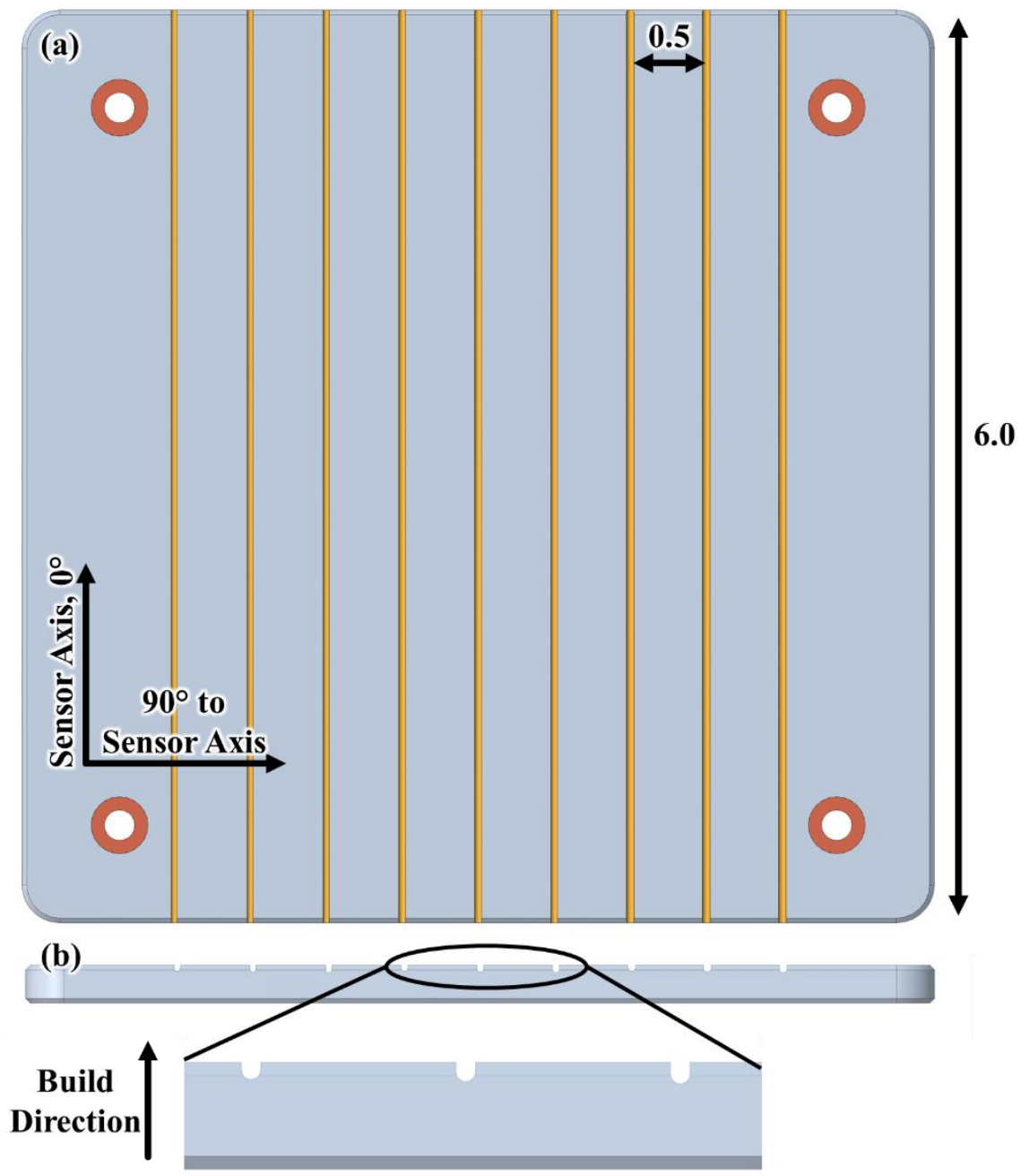

Figure 2. Schematic of the (a) top and (b) side views of the build plates used for embedding the sheaths and thermocouples in SS316. All units shown are in inches.

Table 1. List of channel dimensions and LPBF processing parameters used to embed the sheaths and thermocouples.

\begin{tabular}{|c|c|c|c|c|c|}
\hline Sample embedded & $\begin{array}{l}\text { Sample Diameter } \\
\text { (in.) }\end{array}$ & $\begin{array}{l}\text { Channel width } \\
\text { (in.) }\end{array}$ & $\begin{array}{l}\text { Channel depth } \\
\text { (in.) }\end{array}$ & Dwell time $(\mu \mathrm{s})$ & $\begin{array}{c}\text { First layer scan angle } \\
\left({ }^{\circ}\right)\end{array}$ \\
\hline \multirow{4}{*}{ Sheaths } & \multirow{6}{*}{0.04} & 0.04 & \multirow{4}{*}{$0.04,0.045,0.05$} & \multirow{3}{*}{$40,60,80,100$} & \multirow{3}{*}{0,90} \\
\hline & & 0.045 & & & \\
\hline & & & & & \\
\hline & & 0.05 & & $\begin{array}{c}80,90,100,110,120,130 \\
140,150\end{array}$ & \multirow{3}{*}{90} \\
\hline \multirow{2}{*}{ Thermocouples } & & 0.04 & $0.04,0.045$ & \multirow{2}{*}{100} & \\
\hline & & 0.045 & 0.04 & & \\
\hline
\end{tabular}


Gas-atomized SS316 powders were acquired from Praxair Surface Technologies with the nominal compositions listed in Table 2. The SS316 powder was processed with a Renishaw AM250 for all embedding work. The Renishaw AM250 is equipped with a pulsed, Yb-fiber laser with a spot size and wavelength of approximately 70 and $1.07 \mu \mathrm{m}$, respectively. Ar was flowed into the chamber after a vacuum pump to limit $\mathrm{O}_{2}$ content in the build chamber below 5,000 ppm. The build plate preheat temperature was set to $80{ }^{\circ} \mathrm{C}$.

Table 2. Nominal composition of the SS316L powder acquired from Praxair.

\begin{tabular}{|c|c|}
\hline Element & Content (wt.\%) \\
\hline $\mathrm{C}$ & 0.030 \\
\hline $\mathrm{Mn}$ & 2.00 \\
\hline $\mathrm{P}$ & 0.045 \\
\hline $\mathrm{S}$ & 0.030 \\
\hline $\mathrm{Si}$ & 0.75 \\
\hline $\mathrm{Cr}$ & $16.0-18.0$ \\
\hline $\mathrm{Ni}$ & $10.0-14.0$ \\
\hline $\mathrm{Mo}$ & $2.00-3.00$ \\
\hline $\mathrm{Co}$ & 0.10 \\
\hline $\mathrm{Fe}$ & Bal. \\
\hline
\end{tabular}

For the embedding work, SS316 sheaths and thermocouples were spot welded inside the channels with a resistive spot welder to ensure that they would not move or deform during LPBF processing. Afterward, the surface of the plate was wiped with a semi-abrasive pad to remove any burrs that protruded above the surface of the plate. To embed the sheaths/thermocouples, simple blocks were designed to be printed on top of each thermocouple with dimensions of $25 \times 12 \times 5 \mathrm{~mm}$. The sheaths and thermocouples were embedded via the processing parameters described in Table 1.

\subsection{MICROSTRUCTURAL CHARACTERIZATION}

The samples with embedded sheaths, as well as select samples with embedded thermocouples, were cross-sectioned, cold-mounted in epoxy, and polished to a final finish with $0.05 \mu \mathrm{m}$ colloidal silica. All samples were mounted parallel to the build direction, which is perpendicular to the sensor's axis as shown in Figure 2. For initial inspection and visual analysis, all samples were imaged with optical microscopy (OM, Zeiss Z2m). Select samples were chosen for further microstructural characterization by using scanning electron microscopy (SEM). The samples were analyzed with a field-emission SEM (Tescan Mira3) operated at $20 \mathrm{kV}$.

\subsection{MECHANICAL TESTING}

To test the sensitivity of the LPBF SS316 to the LPBF processing, the hardness of the samples measured with Vickers microhardness (LECO M-400-H2) by using a load of $2 \mathrm{~kg}$ and a holding time of $10 \mathrm{~s}$. A larger load of $2 \mathrm{~kg}$ was chosen to make large indents that were clear enough to measure on the hard steel surface. All indentations were taken on the polished surfaces of the samples. Five indents were taken on each sample for estimating a standard deviation. 


\subsection{THERMAL TESTING}

The embedded thermocouples were subjected to thermal testing to assess sensor functionality after the embedding procedure. The sensors were tested in a controlled furnace (Evenheat HF TAP) while ramping the temperature to $100{ }^{\circ} \mathrm{C}$ and then in $100{ }^{\circ} \mathrm{C}$ increments up to $500{ }^{\circ} \mathrm{C}$. The temperature was held for $60 \mathrm{~min}$ before ramping to the next temperature. An additional nonembedded thermocouple identical to the embedded thermocouples was added to the furnace for comparison. All thermocouples were placed near the furnace's control thermocouple to keep the temperatures as close as possible to the desired setpoints. Temperature data were recorded with a data logger (Squirrel, Grant Instruments) during the experiment.

\section{RESULTS AND DISUCSSIONS}

\subsection{EFFECT OF LPBF PROCESSING ON SAMPLE FABRICATION}

The recommended parameters from Renishaw for printing SS316 include a laser power of $195 \mathrm{~W}$, a point distance of $60 \mu \mathrm{m}$, a dwell time of $80 \mu \mathrm{s}$, a hatch spacing of $100 \mu \mathrm{m}$, a slice thickness of $50 \mu \mathrm{m}$, and a scan rotation of $67^{\circ}$. Because the varying channel widths and depths might affect the powder distribution, these recommended parameters might no longer be optimum when embedding sensors. Therefore, a preliminary study was conducted by first embedding SS316 sheaths with a diameter of 0.04 in. The point distance, hatch spacing, powder slice thickness, and scan rotation are geometric constraints that will not significantly affect the actual melt pool formed by the laser. Therefore, the melt pool formed will be most influenced by the laser power and dwell time of the laser, which guides the laser speed and the local energy density [13, 22]. The laser power could not be increased past $195 \mathrm{~W}$ on the Renishaw, so dwell time was chosen as the best parameter to vary to explore higher and lower energy inputs. Thus, the laser dwell time was varied, and the remaining parameters were held constant to control the variations in the energy density input of the laser. The direction of the laser scan path on the first layer also warrants consideration. Scanning parallel $\left(0^{\circ}\right)$ vs. perpendicular $\left(90^{\circ}\right)$ to the sheath will cause variations in thermal stresses, which might affect the embedding process. Too much stress can cause the sheaths to curl or deform. However, using the same scan orientation of $0^{\circ}$ and $90^{\circ}$ for every layer is atypical for most parts produced by LPBF because it can lead to unwanted microstructures [23]. Consequently, the preliminary study was conducted with a variation in the laser scan direction of the first layer only, but it was changed to $67^{\circ}$ for the remainder of the build per Renishaw's recommendation. The height of the block that was printed on top of each sensor was set to $5 \mathrm{~mm}$ to ensure that the thermocouples could handle the thermal cycling effect from the LPBF process. All other parameters were set to those recommended by Renishaw. The full list of process parameters used to embed thermocouples is detailed in Table 1. 
For the first build, nine sheaths were spot welded in place with a resistive spot welder. The completed build with embedded sheaths is shown in Figure 3. The build finished without any complications and displayed no visible surface roughness or indications of part failure. A total of 24 blocks, each covering three channels on the build plate, gave 72 different parameter/dimension combinations. Sections that contained each LPBF-built block, embedded sheath, and build plate were machined by using a water jet process. Each section was then metallographically prepared for analysis.

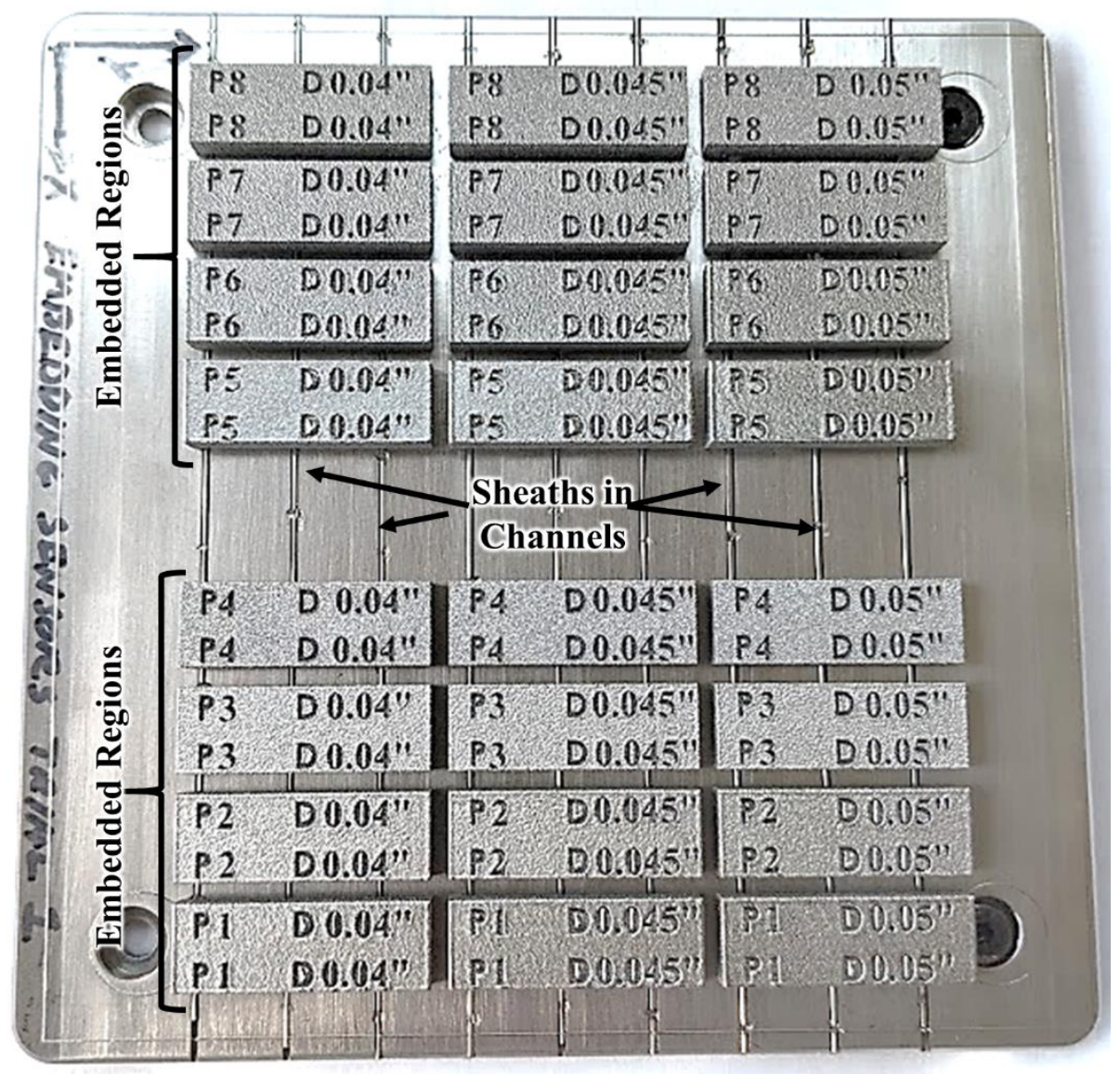

Figure 3. Photo of the completed builds with embedded sheaths. The samples P1-P4 and P5-P8 had a first layer scan orientation of $0^{\circ}$ and $90^{\circ}$, respectively. The samples labeled P1 and P5 were scanned with a laser dwell time of $100 \mu \mathrm{s}, \mathrm{P2}$ and P6 using $80 \mu \mathrm{s}, \mathrm{P3}$ and P7 with $60 \mu \mathrm{s}$, and P4 and P8 at $40 \mu \mathrm{s}$.

$\mathrm{OM}$ images of the cross sections of the embedded sheaths with $0^{\circ}$ and $90^{\circ}$ orientations for the first layer are shown in Figure 4(a) and Figure 4(b), respectively. With respect to Figure 3, the samples in Figure 4(a) and Figure 4(b) correspond to the blocks labeled P1-P4 and P5-P8, respectively. Moreover, samples labeled P1 and P5 were scanned with a laser dwell time of $100 \mu \mathrm{s}, \mathrm{P} 2$ and P6 using $80 \mu \mathrm{s}, \mathrm{P} 3$ and P7 with $60 \mu \mathrm{s}$, and P4 and P8 at $40 \mu \mathrm{s}$. Overall, the sheaths with the smallest width and depth appear to be most effectively embedded. Little to no bonding between the LPBF built region and sheath was observed when depths of 0.05 in. were used. The only differences between Figure 4(a) and Figure 4(b) appears to be the possibility of sheath penetration when a first layer scan orientation of $0^{\circ}$ is used. It is not completely clear, but the circularity of the sheaths processed with a longer dwell time of $100 \mu \mathrm{s}$ appears irregular, which could be due to possible laser penetration. Because this irregularity was not observed in Figure 4(b) for the $90^{\circ}$ orientation, all subsequent sensor embedding used a $90^{\circ}$ scan orientation for the first layer. 
(a)

0.04 in Channel Width
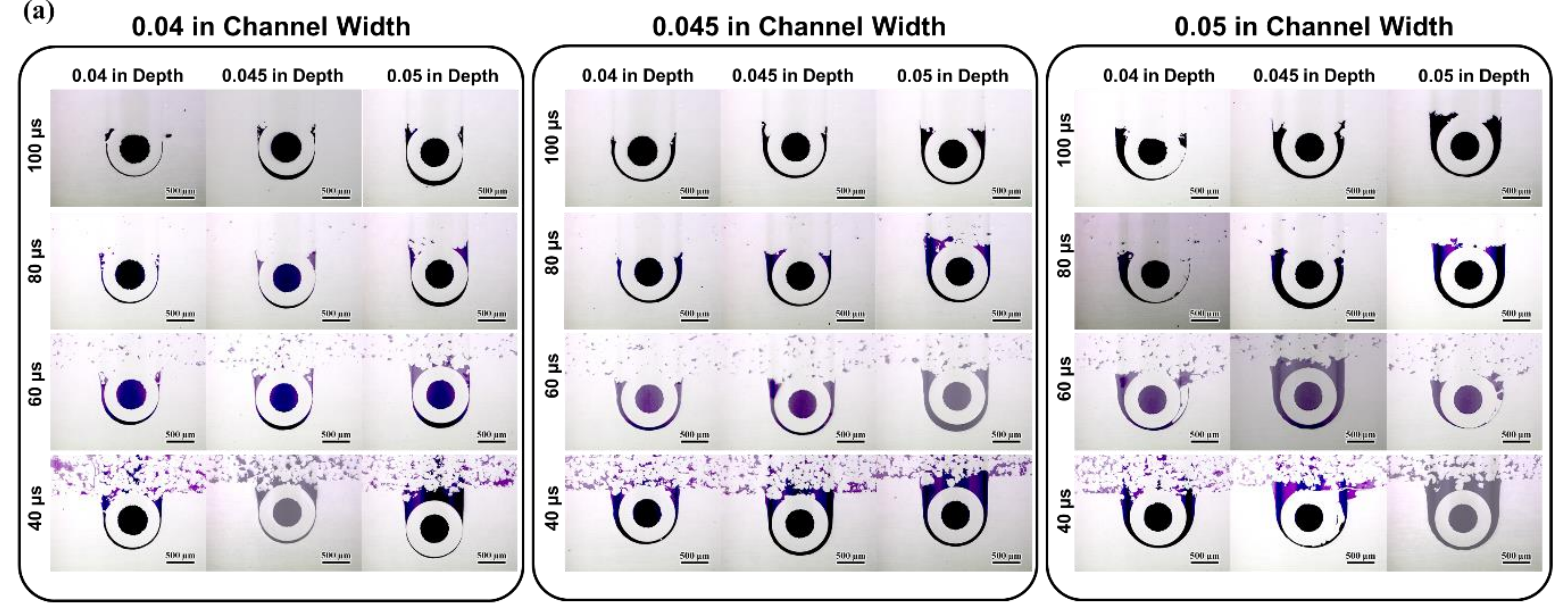

(b)
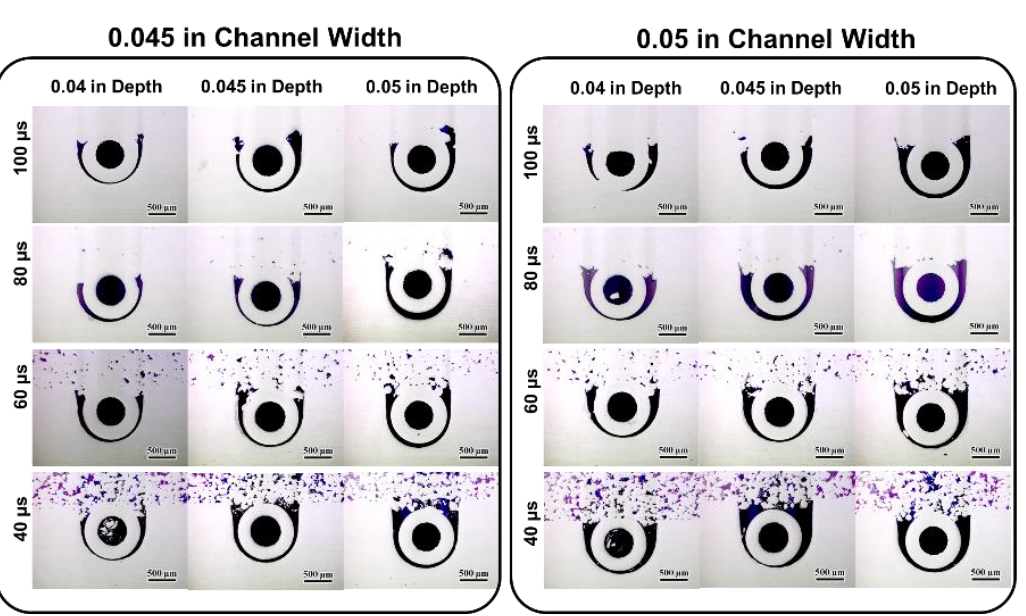

Figure 4. OM images of the cross sections of the embedded sheaths that were processed with a first layer scan orientation of (a) $0^{\circ}$ and (b) $90^{\circ}$.

To quantify the quality of the embedded sheaths/thermocouples, the amount of "open space" observed around the sheaths and thermocouples was measured with ImageJ (National Institutes of Health). All OM images were taken at a $100 \times$ magnification. A square was drawn and mounted at the bottom-center of the channel, as shown in Figure 5(a). The maximum channel depth/width was 0.05 in. $(1,271 \mu \mathrm{m})$; therefore, the dimensions for the square were chosen to be $1,300 \times 1,300 \mu \mathrm{m}$. Using the positioned square, the image was cropped to remove any effects from the remainder of the image, as shown in Figure 5(b). Next, the image was converted to an 8 bit image, so a black and white threshold could be used to measure the amount of unfilled space (white regions) with respect to the filled regions (dark regions), as shown in Figure 5(c) and Figure 5(d). This method was chosen as the best way to standardize the measurements throughout each sample series. Because the embedded sheaths were used to test variations in dwell time, the porosity content in the region built with LPBF is also expected to vary. Therefore, the region built by LPBF was subjected to porosity analysis, again by using the 8 bit thresholding method - as shown in Figure 5(e), Figure 5(f), and Figure 5(g) - to measure the amount of unfilled space (i.e., porosity). Porosity analysis is based on five images taken along the LPBF built section. In these cases, the image magnification was set to $50 x$. 

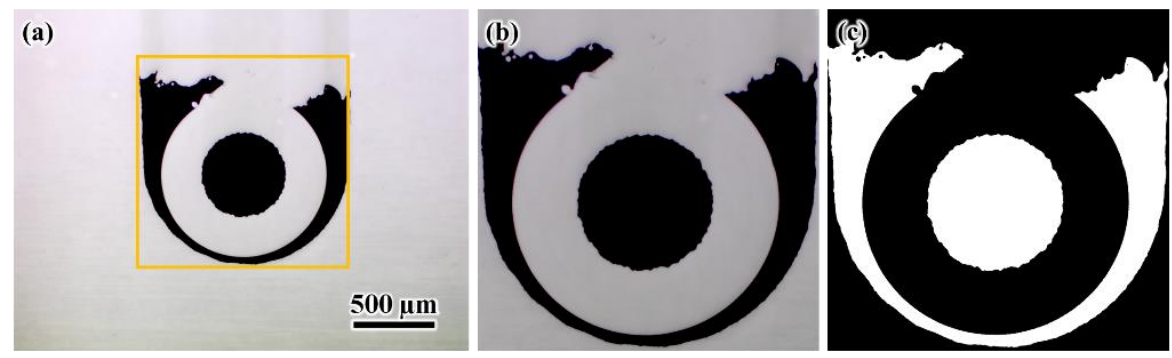

(d)
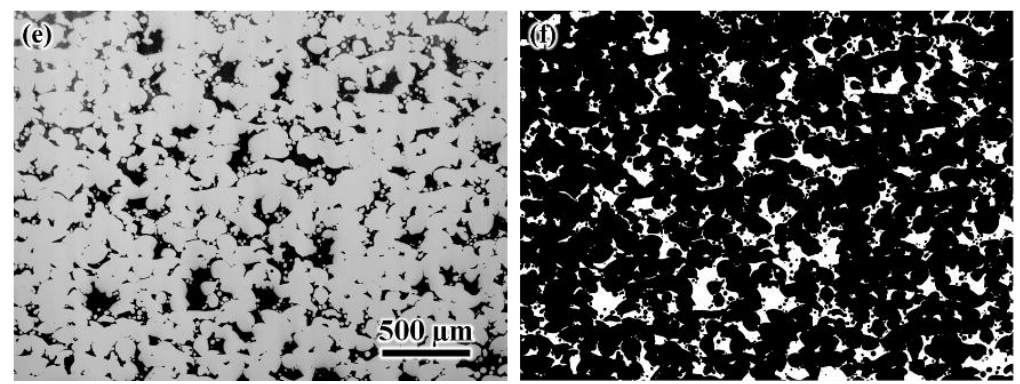

(g)

Figure 5. Examples of image analysis performed (a-d) for the amount of open space around the embedded sheaths/thermocouples and $(\mathrm{e}-\mathrm{g})$ for the porosity content in the region built with LPBF. Image analysis was performed by first (a, b, e) importing and selecting the desired the region, (c, f) applying an 8 bit threshold, and (d, g) measuring the area of white space compared with the area of dark space.

The results of the image analysis described in Figure 5(a-d) are shown in Figure 6. In Figure 6, the amount of open space was quantified as an area and compared with the expected area from the product of the channel width $\times$ depth. For both first layer scan orientations, the amount of open space is highly dependent on the width/depth combination. As shown in Figure 4, the use of smaller dimensions (i.e., 0.04 in. for width/depth) yields less of an open space between the sheath and matrix. For thermocouples, the main goal is to embed enough of the sheath with the matrix, which was clearly achieved at the use of larger dimensions. However, the gap between the sheath/thermocouple and the matrix will increase the thermal time constant, resulting in a delayed response to a step change in temperature and/or reactor power. Therefore, the least amount of open space is desired, as was achieved by using a width/depth of 0.04 in. 

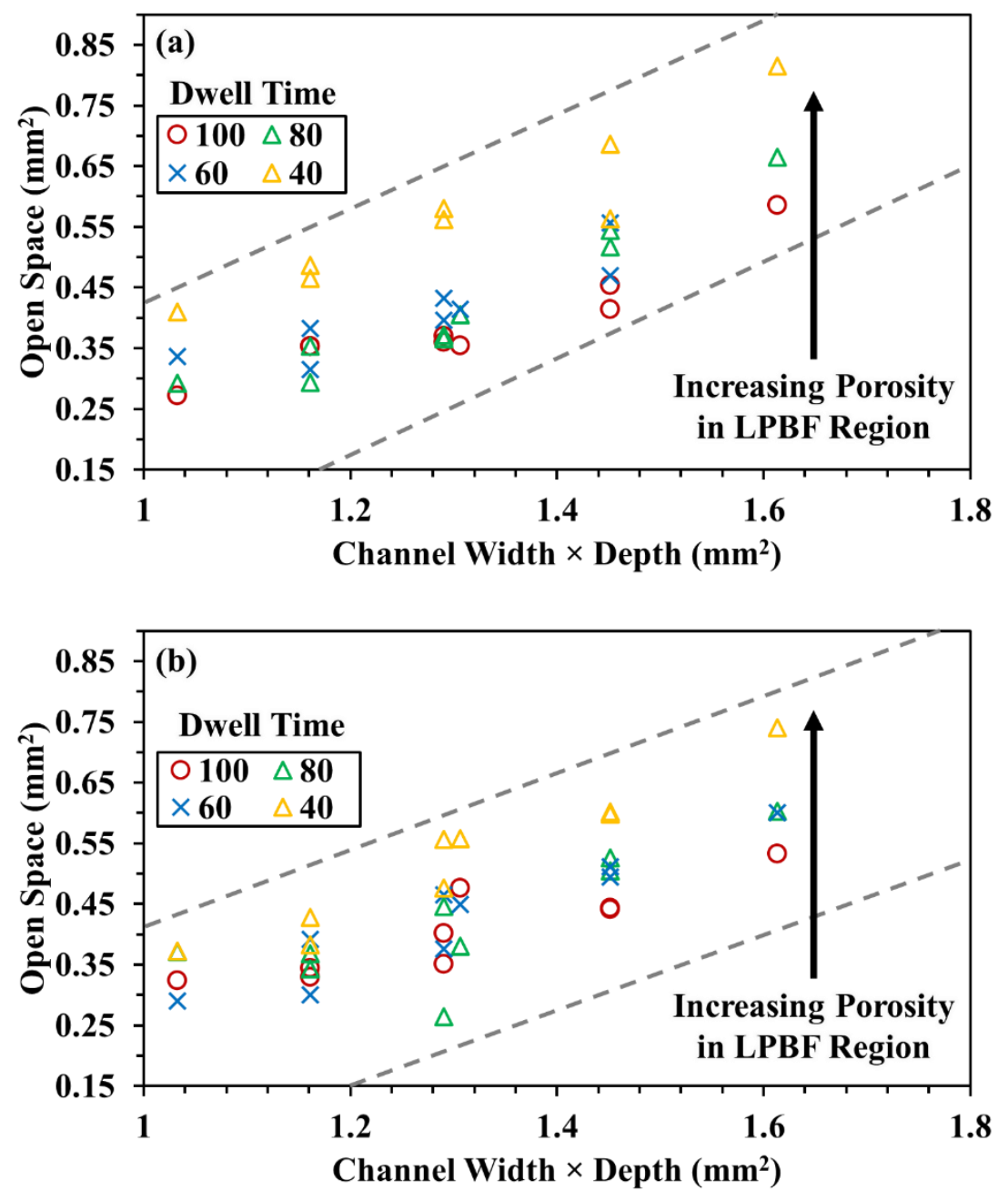

Figure 6. Results of the image analysis for the embedded sheaths showing the measured open space of the channel compared with the expected area of the channel width $\times$ depth for the samples with a first scan layer orientation of (a) $0^{\circ}$ and (b) $90^{\circ}$. Data are shown as a function of dwell time. The drawn parallel lines indicate the overall trend of the data. In (a), the $60 \mu$ s sample with a width and depth of 0.05 in. had an approximate open space of $1.31 \mathrm{~mm}^{2}$, due to a large amount of porosity observed in the LPBF built region, and is therefore not shown on the plot.

Figure 4 shows how porosity generally increases with decreasing dwell time. This can affect the results shown in Figure 6 because the LPBF built region is included in the region considered by the bounding box used in Figure 5(a). Therefore, porosity analysis was performed on the LPBF built region by using an 8-bit threshold on optical images, as shown in Figure 5(e-g). In conjunction, Vickers hardness testing was performed on the LPBF built region as a function of dwell time. Porosity analysis and hardness testing were only performed on the blocks that covered the channels with a width of $0.05 \mathrm{in}$. because of repetition of similar samples and to limit destructive testing of the samples with smaller channel dimensions that might be used for future analyses. 
Figure 7 shows the results of the porosity analysis and Vickers hardness testing. Overall, porosity decreased with increasing dwell time, as shown in Figure 7(a). Consequently, the Vickers hardness was shown to increase with increasing dwell time, most likely due to the decreases in porosity with increasing dwell time. The sample processed with a dwell time of $100 \mu$ s exhibited the least amount of porosity and appears the most visually dense, as shown in Figure 7(b). Renishaw's recommended parameter set includes a dwell time of $80 \mu \mathrm{s}$, but a higher degree of porosity was observed by using this dwell time (Figure 7[c]) compared with to using a $100 \mu$ s dwell time (Figure 7[b]). However, the overall porosity content at $80 \mu$ s was $<1 \%$. Going below a dwell time of $80 \mu$ s clearly resulted in significantly higher porosity content, most likely due to the lack of fusion between the powder particles, as shown in Figure 7(d) and Figure 7(e). Moreover, partially melted particles can be observed in the microstructure in Figure 7(e) for a dwell time of $40 \mu \mathrm{s}$. The porosity observed is reflected in the open space results shown in Figure 7. As shown in Figure 7(a) and Figure 7(b), a shorter dwell time led to a high degree of open space.

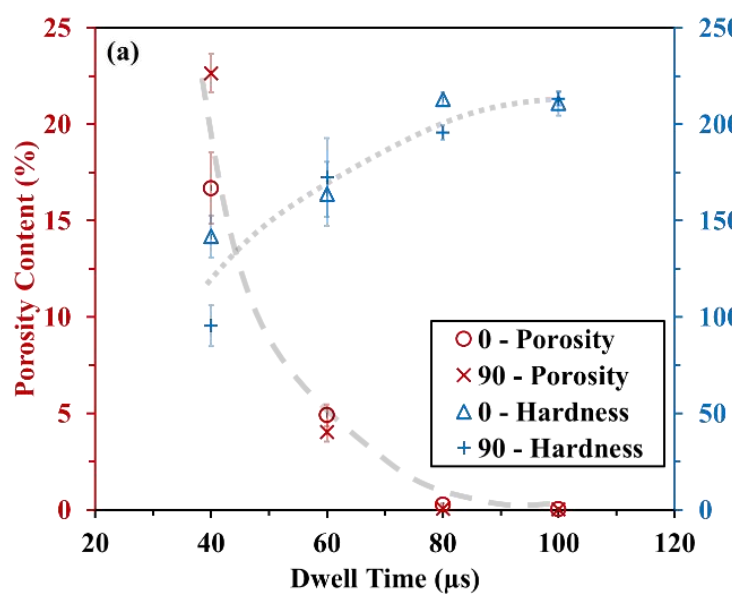

(b)

(c)

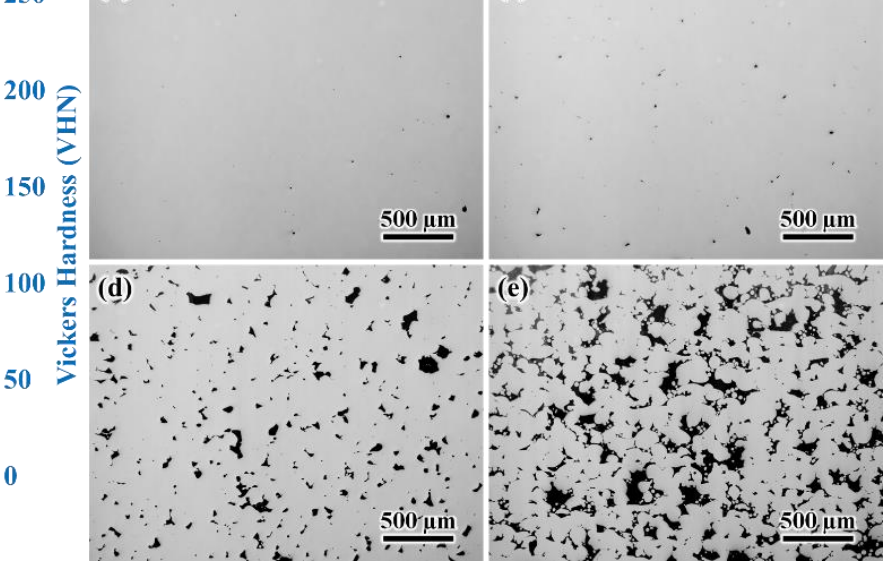

Figure 7. (a) Plotted porosity content and Vickers hardness of the LPFB build region vs. the dwell time used to process that region. (b-e) OM images of the LPBF built region using dwell times of (b) 100, (c) 80, (d) 60, and (e) $40 \mu \mathrm{s}$. The lines in (a) indicate the overall trend.

\subsection{MICROSTRUCTURAL ANALYSIS OF EMBEDDED SHEATHS}

The embedding process requires the partial melting of the sheath or capillary that contains the sensor. Empty sheaths with a wall thickness of $250 \mu \mathrm{m}$ were chosen as a surrogate for thermocouples to observe any ruptures from the laser penetrating past the wall thickness. The microstructural analyses of select samples scanned at a dwell time of $100 \mu$ s with embedded sheaths were imaged with an SEM, and the results are shown in Figure 8. The samples imaged in Figure 8(a,c) and Figure 8(b, d) are shown for scanning orientations of $0^{\circ}$ (parallel to the sheath) and $90^{\circ}$ (perpendicular to the sheath), respectively. As mentioned previously, this scanning orientation was performed only on the first layer to determine whether the laser path impacted the melt pool near the sheath/matrix interface.

As shown in Figure 8(a) and Figure 8(b), the sheath did not rupture when using the optimized dwell time of $100 \mu \mathrm{s}$, regardless of the scanning orientation. In both samples, only about $\sim 150 \mu \mathrm{m}$ of the sheath were melted and fused with the additional layers from the powder bed process. Interestingly, the interface in Figure 8 (a) for the $0^{\circ}$ scan orientation appears undulated with a somewhat sinusoidal curvature. On the other hand, the interface between the sheath and LPBF built region in Figure 8(b) for the scan orientation of $90^{\circ}$ is flat. The grain structure in the fused region directly above the sheath is columnar for the $0^{\circ}$ orientation, as shown in Figure 8(c), which is a typical grain structure for LPBF SS316 [24]. However, the grain structure in the fused region above the sheath for the $90^{\circ}$ orientation is refined and somewhat 
equiaxed, as shown in Figure 8(d). Columnar-type structures are more susceptible to crack propagation because cracks can easily evolve along the long grain boundaries. A more equiaxed structure resists crack propagation and is more preferred for increased isotropic mechanical properties. Although the sheaths in Figure 8(a,c) were not ruptured as initially thought based on the OM images in Figure 4(a), it is best to avoid using the $0^{\circ}$ scan orientation on the first layer because it leads to a less favorable grain structure at the interface.
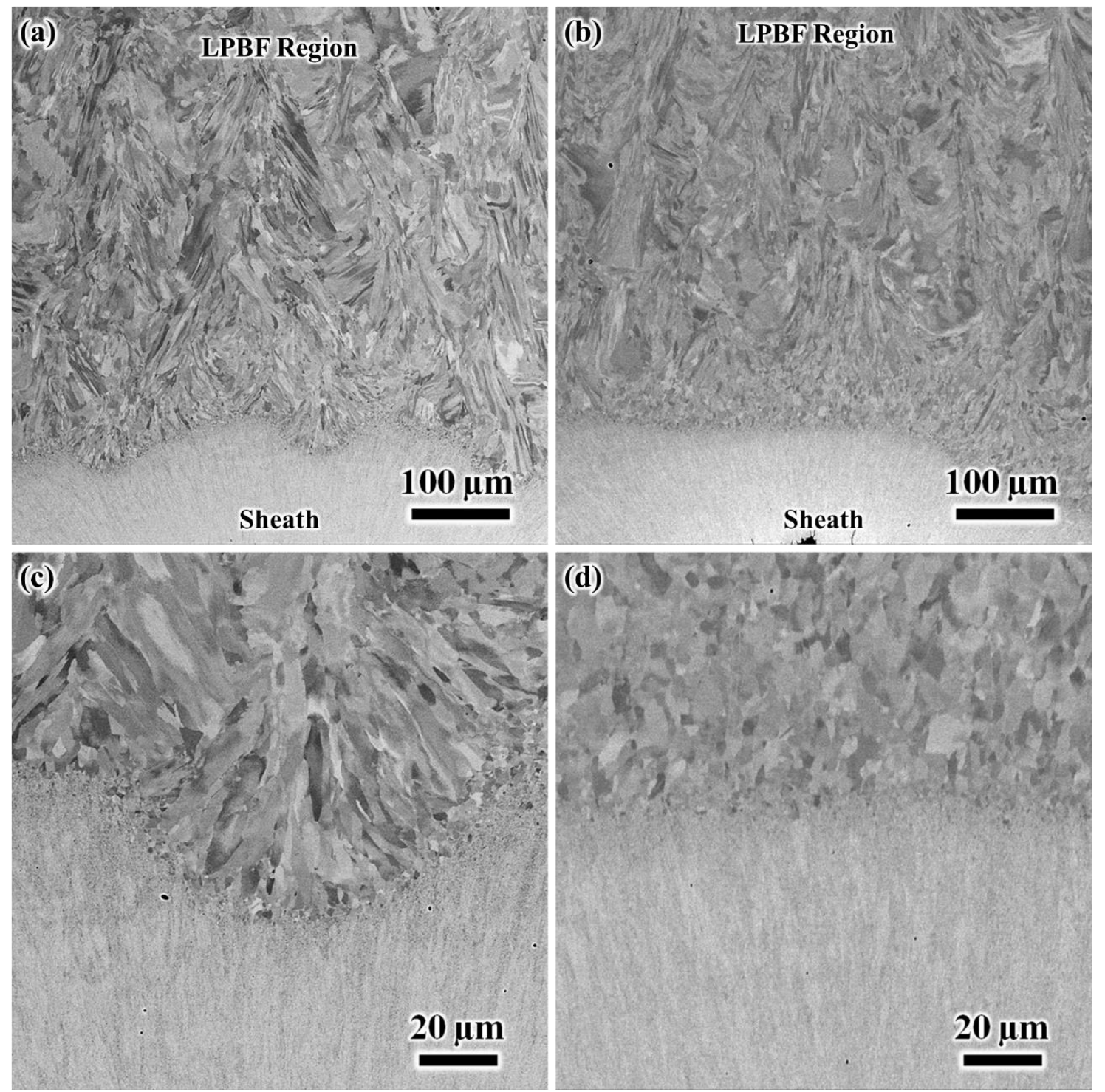

Figure 8. (a, b) Low and (c, d) high magnification backscatter electron micrographs showing the interface between the embedded sheath and the LPBF built region when using a first layer scan orientation of (a, c) $0^{\circ}$ and (b, d) $90^{\circ}$. The sheath shown was embedded in a channel with a width/depth of 0.04 in., shown to yield the best result for embedding the sheaths. 


\subsection{EMBEDDED THERMOCOUPLE CHARACTERIZATION}

Based on the results shown in Figure 4 and Figure 6, the smallest channel dimensions were found to be optimum for embedding sensors because these dimensions minimized the amount of open space between the sensor and matrix. Because the same baseplate geometry was used to embed thermocouples, only one channel used a 0.04 in. width and $0.04 \mathrm{in}$. depth. Therefore, in addition to this channel geometry, some of the thermocouples were embedded in the next smallest channels: $0.04 \mathrm{in}$. wide and $0.045 \mathrm{in}$. deep, and $0.045 \mathrm{in}$. wide and $0.04 \mathrm{in}$. deep. Type-K thermocouples were embedded from both sides of the plate to double the number of specimens so that three could be used for thermal testing and the other three could be used for metallography and microscopy. For LPBF processing over the sensors, a dwell time of $100 \mu \mathrm{s}$ was used because it yielded the least amount of porosity, as per Figure 7. The first layer scan orientation was set to $90^{\circ}$ (perpendicular to the sensor length) to capitalize on the refined grain structure produced near the interface of the sheath and the LPBF built region, as observed in Figure 8. The finished build is shown in Figure 9. As shown in Figure 9, additional sheaths were embedded on the right-hand side of the build plate in the higher width channels ( 0.05 in. wide). These sheaths were embedded to explore the LPBF processing regime further using higher dwell times. The embedded thermocouples/sheaths were sectioned from the build plate using a water jet machine.

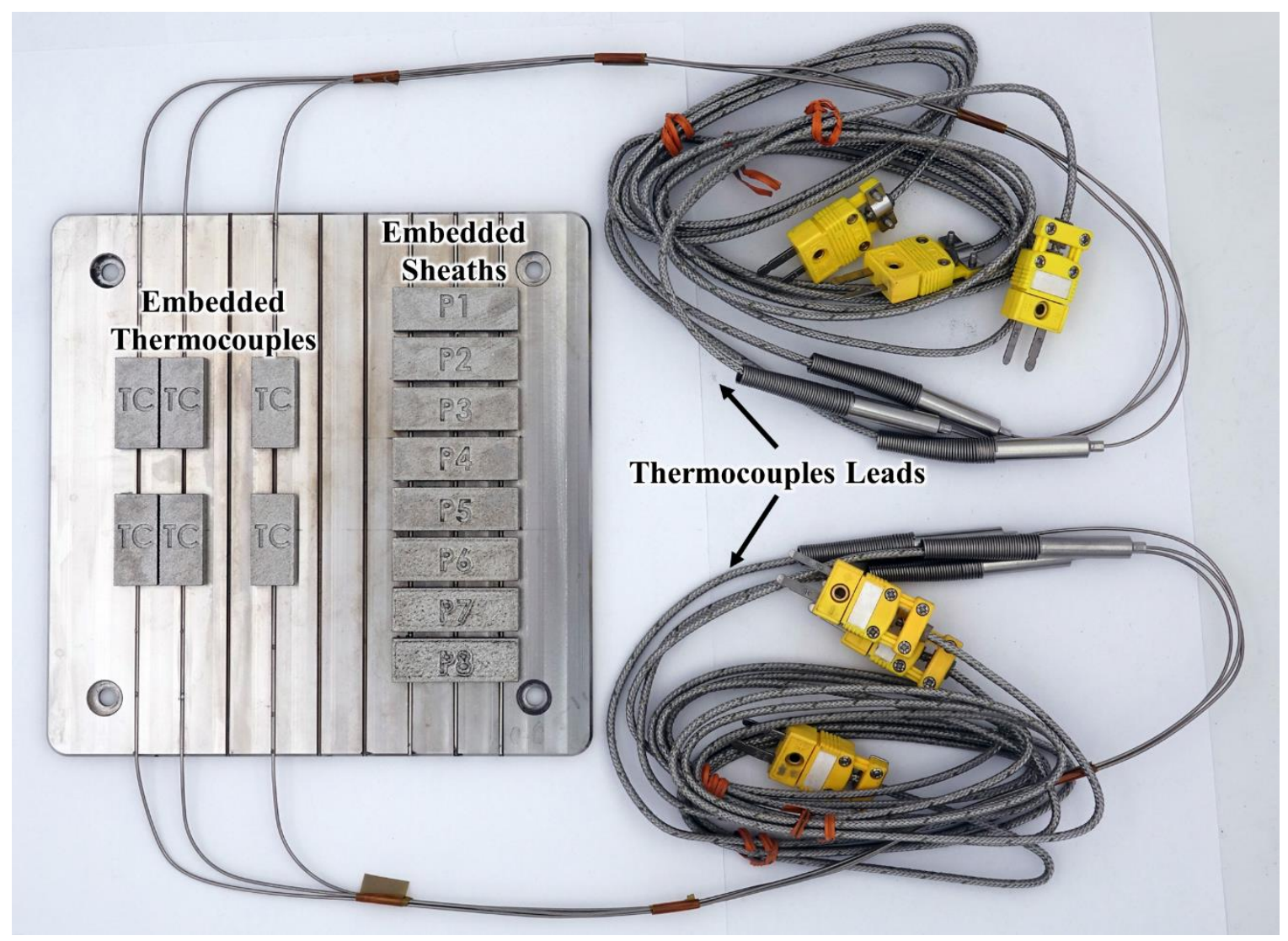

Figure 9. Photo of the embedded thermocouples post-LPBF-processing. Six thermocouples were embedded in select channel cavities based on results from the parametric investigation with the embedded sheaths. Additional sheaths were embedded on the right-most channels of the plate to further explore the LPBF processing regime. 
Three embedded thermocouples were sectioned and mounted for microscopy to observe the quality of the embedding within the SS316 matrix. OM images of cross sections of the sensors are shown in Figure 10. Overall, the top of each sensor is well bonded with the SS316 matrix. Moreover, the $\mathrm{MgO}$ electrical insulation around the thermocouple leads does not appear to be damaged by the laser. As expected, the least amount of open space around the sensor was observed in Figure 10(a, c) for the channel with a 0.04 in. width and 0.04 in. depth. Unfortunately, a defect was observed over the top of the sensor, but this appeared to be due to the manufacturing of the sensor, not a result of the LPBF process. Using a larger width of 0.045 in., as shown in Figure 10(c, f), created more open space and observable porosity in the LPBF built region above the sensor, similar to what was observed when embedding the empty sheaths. Similarly, minor porosity was observed over the top of the sensor embedded in the channel with a 0.04 in. width and 0.045 in. depth; the larger depth was barely enough to impact the density of the LPBF built region.

(a)

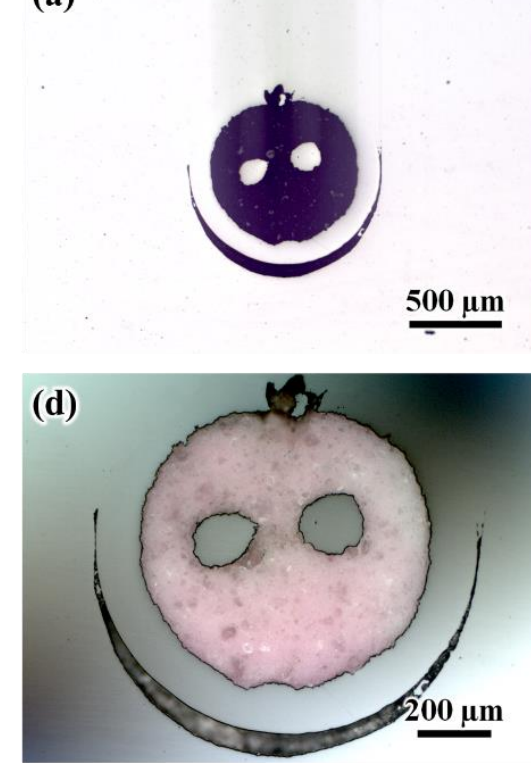

(b)
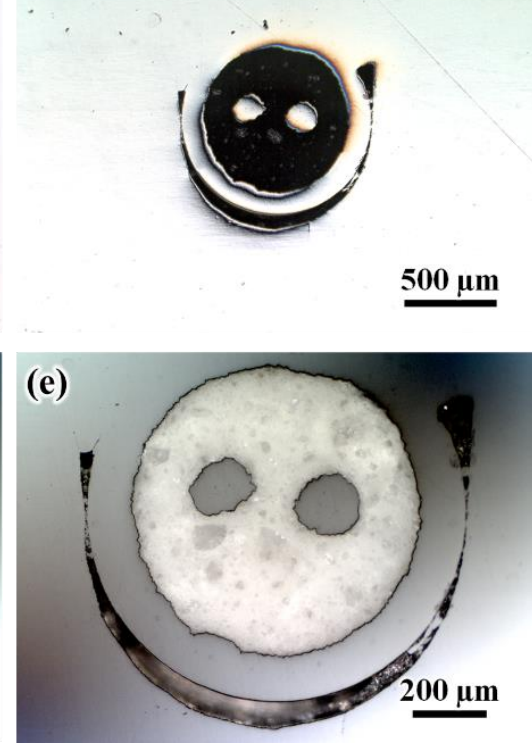
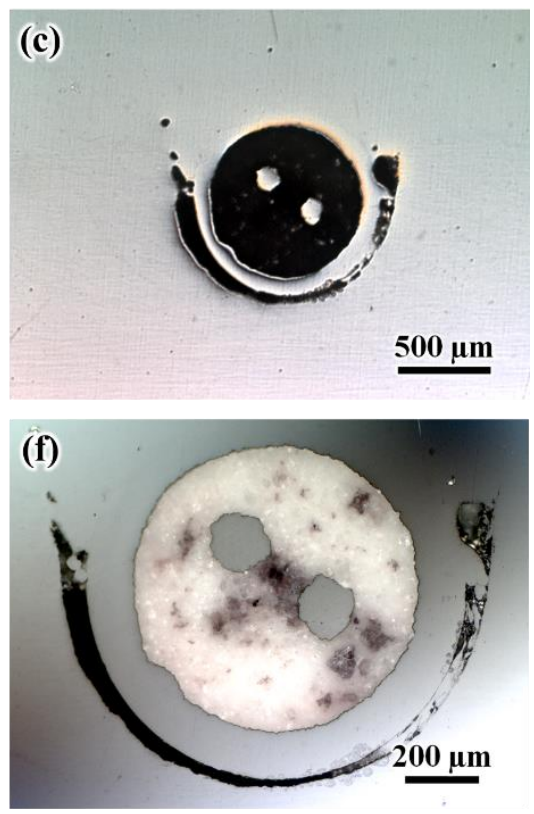

Figure 10. (a-c) Low and (d-f) high magnification $O M$ images of the cross section of the embedded thermocouples with corresponding channel dimensions of (a, d) 0.04 in. wide and 0.04 in. deep, (b, e) 0.04 in. wide and 0.045 in. deep, and (c, f) 0.045 in. wide and 0.04 in. deep.

The three embedded thermocouples that were not sectioned were subjected to thermal testing in a furnace. The temperature was increased to $100{ }^{\circ} \mathrm{C}$ and then incremented in $100{ }^{\circ} \mathrm{C}$ steps up to $500{ }^{\circ} \mathrm{C}$, holding for 60 min at each step. This testing covers most of the expected operating range for the TCR core, which is approximately $350-550^{\circ} \mathrm{C}$. A nonembedded thermocouple was also added to the furnace to serve as a reference. The sensors were placed near the furnace's control thermocouple at the center of the furnace to keep the temperatures as close to the desired setpoint as possible. The acquired data are shown Figure 11. 


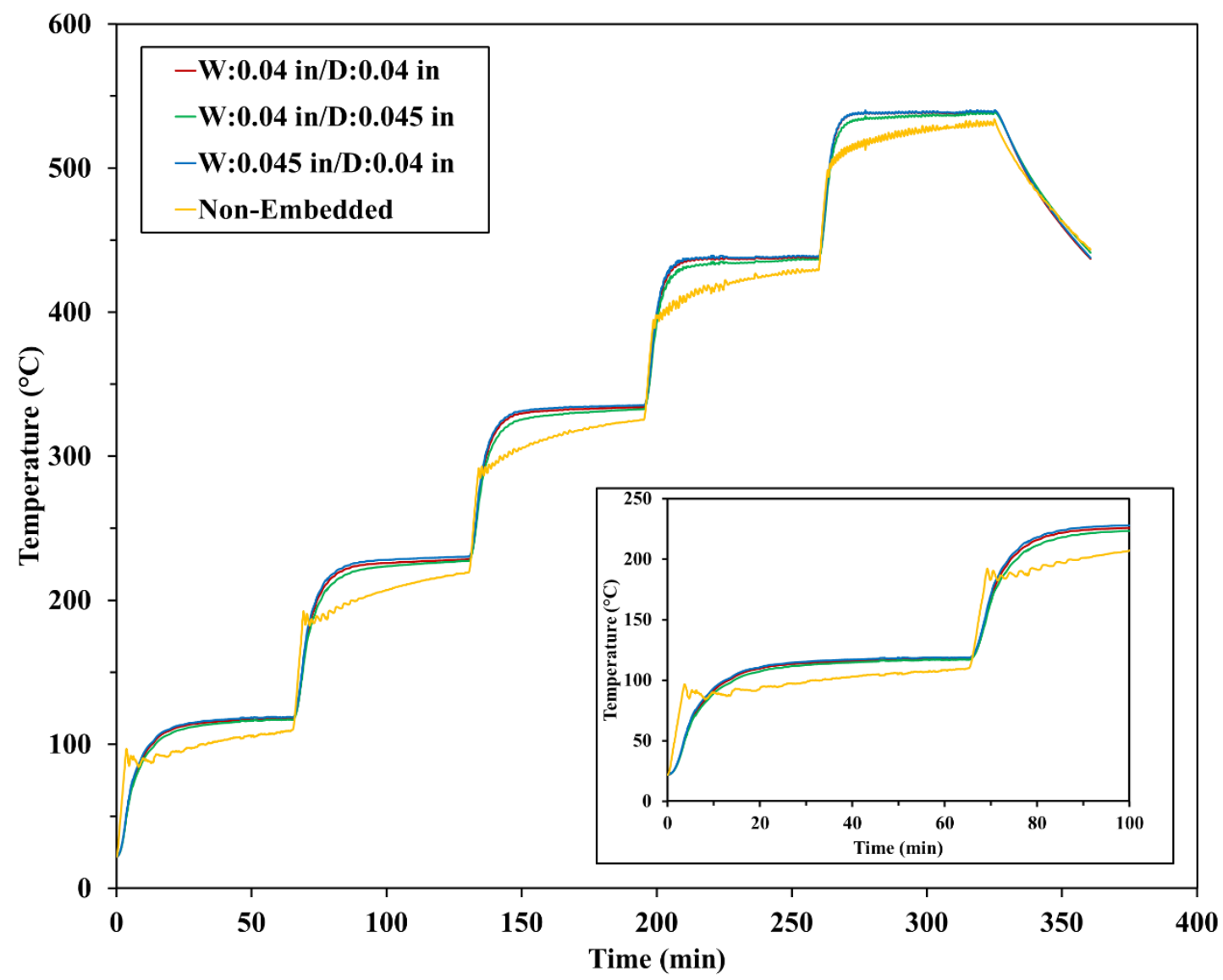

Figure 11. Recorded temperatures of thermocouples during furnace heating to $500{ }^{\circ} \mathrm{C}$. The inset plot shows the high consistency between the three embedded thermocouples compared with a nonembedded thermocouple.

Overall, the temperature readings of the three embedded thermocouples were consistent with each other. Compared with the nonembedded thermocouple that was located near the embedded samples, the embedded thermocouples initially measured lower temperatures during each step in temperature. However, the temperatures measured by the embedded thermocouples eventually increased beyond those of the nonembedded thermocouple. With further heating, the nonembedded thermocouple temperatures eventually started to approach those of the embedded thermocouples. The differences in ramping rate to each temperature could be due to the time constant associated with heating the SS316 block that contains the embedded thermocouples, which is much different than that of the nonembedded thermocouple. If the thermocouples were allowed to reach a steady state, then all four thermocouples would likely read the same temperatures. 


\section{SUMMARY}

This report details the processing strategies used for embedding thermocouples in an SS316 matrix using LPBF. Custom build plates were designed with machined cavities in the form of channels within which the sensors were placed before layering additional material over the top, thereby embedding them using LPBF. Empty sheaths were used as a surrogate in preliminary testing to explore the LPBF processing regime and determine the optimum channel geometry to ensure good bonding with the matrix. This testing showed that shorter laser dwell times and larger channel dimensions resulted in larger gaps between the sheath and the bottom of the channel, as well as increased porosity in the LPBF built regions. Thermocouples were embedded by using the optimized LPBF parameters in channels with the smallest channel dimensions. The tops of the thermocouples were observed to be well embedded with the SS316 matrix with no damage to the $\mathrm{MgO}$ electrical insulation, suggesting that the laser did not penetrate beyond the sensor housing wall. Furthermore, the sensors were subjected to furnace testing to temperatures up to $500{ }^{\circ} \mathrm{C}$, during which all three embedded thermocouples were consistent with one another. There was a difference in the transient response of the embedded thermocouples compared with the nonembedded thermocouple, most likely due to the difference in thermal time constants. Results showed that the nonembedded thermocouple read temperatures that were approaching those measured by the embedded thermocouples with increasing time during each step increase in temperature. These results indicate that

LPBF processing can be used to embed sensors in SS316 matrices, and the knowledge gained during this testing will be leveraged for future work that focuses on embedding sensors in relevant TCR reactor components and eventually testing those components under neutron irradiation.

\section{REFERENCES}

[1] B. Betzler, B. Ade, A. Wysocki, P. Jain, P. Chesser, M. Greenwood, K. Terrani, Transformational Challenge Reactor preconceptual core design studies, Nucl. Eng. Des. 367 (2020) 110781.

[2] X. Hu, T.G. Lach, K.A. Terrani, Deuterium permeation and retention in 316L Stainless Steel Manufactured by Laser Powder Bed Fusion, J. Nucl. Mater. 548 (2021) 152871.

[3] C.M. Petrie, A.M. Schrell, D.N. Leonard, Y. Yang, B.C. Jolly, K.A. Terrani, Embedded sensors in additively manufactured silicon carbide, J. Nucl. Mater. 552 (2021) 153012.

[4] C.M. Petrie, A. Schrell, D. Leonard, B.C. Jolly, Demonstration of Embedded Sensors in Ceramic Structures, Oak Ridge National Lab.(ORNL), Oak Ridge, TN (United States), 2020.

[5] N.D. See, B. Betzler, S. Cetiner, Design Optimization of the Transformational Challenge Reactor Outlet Plenum, Nucl. Sci. Eng. (2021).

[6] B. Soller, M. Wolfe, M. Froggatt, Polarization resolved measurement of Rayleigh backscatter in fiberoptic components, National Fiber Optic Engineers Conference, Optical Society of America, 2005, p. NWD3.

[7] B.J. Soller, D.K. Gifford, M.S. Wolfe, M.E. Froggatt, High resolution optical frequency domain reflectometry for characterization of components and assemblies, Opt. Express 13(2) (2005) 666-674.

[8] C.M. Petrie, D.P. Hawn, W. Windl, T.E. Blue, Reactor radiation-induced attenuation in fused silica optical fibers heated up to 1000 C, Journal of Non-Crystalline Solids 409 (2015) 88-94.

[9] R. Gottschlich, M. Bellezza, EMF Deviation of Chromel/Alumel Thermocouples Caused by Neutron Irradiation (Irradiation Experiment TIC-01). EUR 3257, (1966).

[10] D.C. Sweeney, A.M. Schrell, C.M. Petrie, An Adaptive Reference Scheme to Extend the Functional Range of Optical Backscatter Reflectometry in Extreme Environments, IEEE Sens. J. 21(1) (2021) 498509.

[11] G. Cheymol, H. Long, J.F. Villard, B. Brichard, High Level Gamma and Neutron Irradiation of Silica Optical Fibers in CEA OSIRIS Nuclear Reactor, IEEE Trans. Nucl. Sci. 55(4) (2008) 2252-2258. 
[12] W.J. Sames, F. List, S. Pannala, R.R. Dehoff, S.S. Babu, The metallurgy and processing science of metal additive manufacturing, Int. Mater. Rev. 61(5) (2016) 315-360.

[13] H. Hyer, L. Zhou, S. Park, G. Gottsfritz, G. Benson, B. Tolentino, B. McWilliams, K. Cho, Y. Sohn, Understanding the Laser Powder Bed Fusion of AlSi10Mg Alloy, Metallography Microstructure and Analysis 9(4) (2020) 484-502.

[14] C.M. Petrie, N.D.B. Ezell, Demonstrate embedding of sensors in a relevant microreactor component, Oak Ridge National Lab.(ORNL), Oak Ridge, TN (United States), 2020.

[15] C.M. Petrie, N. Sridharan, A. Hehr, M. Norfolk, J. Sheridan, High-temperature strain monitoring of stainless steel using fiber optics embedded in ultrasonically consolidated nickel layers*, Smart Mater. Struct. 28(8) (2019) 085041.

[16] C.M. Petrie, N. Sridharan, M. Subramanian, A. Hehr, M. Norfolk, J. Sheridan, Embedded metallized optical fibers for high temperature applications, Smart Mater. Struct. 28(5) (2019) 055012.

[17] T. Debroy, H.L. Wei, J.S. Zuback, T. Mukherjee, J.W. Elmer, J.O. Milewski, A.M. Beese, A.

Wilson-Heid, A. De, W. Zhang, Additive manufacturing of metallic components - Process, structure and properties, Prog. Mater Sci. 92 (2018) 112-224.

[18] X. Li, J. Johnson, J. Groza, F. Prinz, Processing and microstructures of fiber Bragg grating sensors embedded in stainless steel, Metall. Mater. Trans. A 33(9) (2002) 3019-3024.

[19] D. Havermann, J. Mathew, W.N. MacPherson, R.R. Maier, D.P. Hand, Temperature and strain measurements with fiber Bragg gratings embedded in stainless steel 316, J. Lightwave Technol. 33(12)

(2014) 2474-2479.

[20] J. Mathew, C. Hauser, P. Stoll, C. Kenel, D. Polyzos, D. Havermann, W.N. MacPherson, D.P. Hand, C. Leinenbach, A. Spierings, Integrating fiber fabry-perot cavity sensor into 3-D printed metal components for extreme high-temperature monitoring applications, IEEE Sens. J. 17(13) (2017) 41074114.

[21] P. Stoll, J. Mathew, A. Spierings, T. Bauer, R. Maier, K. Wegener, Embedding fibre optical sensors into SLM parts, Proceedings of the 27th Annual International Solid Freeform Fabrication (2016) 18151825.

[22] C. Hensley, K. Sisco, S. Beauchamp, A. Godfrey, H. Rezayat, T. McFalls, D. Galicki, F. List, K. Carver, C. Stover, D.W. Gandy, S.S. Babu, Qualification pathways for additively manufactured components for nuclear applications, J. Nucl. Mater. 548 (2021) 152846.

[23] O. Andreau, I. Koutiri, P. Peyre, J.-D. Penot, N. Saintier, E. Pessard, T. De Terris, C. Dupuy, T. Baudin, Texture control of 316L parts by modulation of the melt pool morphology in selective laser melting, J. Mater. Process. Technol. 264 (2019) 21-31.

[24] S. Dryepondt, P. Nandwana, P. Fernandez-Zelaia, F. List, Microstructure and high temperature tensile properties of 316L fabricated by laser powder-bed fusion, Addit. Manuf. 37 (2021) 101723. 
